УДК 330.16

$10.17213 / 2075-2067-2020-6-154-162$

\title{
ОПЫТ ВНЕДРЕНИЯ ИНФОРМАЦИОННЫХ ТЕХНОЛОГИЙ В СФЕРЕ ЗДРАВООХРАНЕНИЯ: ПРОБЛЕМЫ И ПЕРСПЕКТИВЫ
}

\author{
(C) 2020 г. Л. В. Голощапова, Н. П. Савина, К. А. Винидиктова
}

\section{Российский экономический университет имени Г. В. Плеханова, г. Москва, Россия}

Целью исследования является анализ применения информаџионных технологий в сфере здравоохранения и использования определенного метода анализа данных для минимизации доступа к конфиденциальной информации.

Методологическую базу исследования составляют теории и практики российских и зарубежных специалистов по исследованию основных положений компьютерной обработки данныхх.

Результаты исследования. Основной результат - выявление особенностей и проблем проведения ревизии в условиях компьютерной обработки данных, опыта внедрения технологий в сфере здравоохранения государственными учреждениями в связи с переходом на ведение отчетности в электронном виде путем применения определенных систем и баз данных, таких как Медиалог, МедИсследования и др.

Перспективы исследования состоят в более детальном анализе деятельности учреждений здравоохранения, корректировке методов применения российских и зарубежных технологий.

Ключевые слова: информаџионные технологии; ичифровизация; компьютерные даннье; персональнье даннье; здравоохранение; ревизия.

\section{EXPERIENCE IN IMPLEMENTING INFORMATION TECHNOLOGIES IN HEALTHCARE: PROBLEMS AND PROSPECTS}

\author{
(C) 2020 L. V. Goloshchapova, N. P. Savina, K. A. Vinidiktova \\ Plekhanov Russian University of Economics, Moscow, Russia
}

The purpose of the study is to analyze the application of information technologies in the healthcare sector and the use of a specific data analysis method to minimize access to confidential information.

The methodological base of the research consists of the theories and practices of Russian and foreign specialists in the study of the main provisions of computer data processing.

The results of the study. The main result is to identify the features and problems of conducting audits in the context of computer data processing, experience in implementing technologies in the healthcare sector by state institutions in connection with the transition to electronic reporting by using certain systems and databases, such as Medialog, medical Research, etc.

The research prospects consist in a more detailed analysis of the activities of healthcare institutions, adjusting the methods of using Russian and foreign technologies.

Key words: information technologies; digitalization; computer data; healthcare; audit. 
Введение. XXI век - период информатизации и цифровизации, внедрения в жизнь компьютерных технологий взамен бумажных носителей информации. Многие государственные учреждения перешли на электронные базы данных клиентов, записывают их на прием, выписывают лекарства через онлайн-систему здравоохранения, проводят консультации. Проведение проверки финансово-хозяйственной деятельности в период цифровизации становится сложнее, чем раньше [2].

Теоретические основы данных о сфере здравоохранения, полученных посредством внедрения информационных технологий. Рассмотрение темы ревизии компьютерной обработки данных невозможно без использования базовых понятий. Любое представление информации в электронном виде, подходящем для обработки в компьютерной системе, включая разработку, — это компьютерные данные. Их можно классифицировать по определенным признакам (рис. 1).

В сфере здравоохранения цифровизация начала проявляться примерно с 1999 г. с введения ИНН, который существует для физических, юридических лиц и индивидуальных предпринимателей. Данное нововведение по- могло исчислять налоги в различные отрасли здравоохранения, а также увеличить число предоставляемых гражданам услуг, упростило процесс обслуживания. Глобальные изменения происходят как на региональном, так и на федеральном уровнях.

Следующим этапом внедрения электронных данных в систему здравоохранения является введение электронной базы данных для учета инструментария, препаратов, оборудования. Введение данной системы снизило процент сокрытия препаратов и повысило степень открытости сектора здравоохранения. В большинстве медицинских организаций происходит составление и сортировка документации в цифровом формате. Внедрение в медицину информационных технологий в разы улучшило качество услуг, произошла автоматизация бизнес-процессов и создание централизованной системы контроля данных, исключение ошибок и подробная интерпретация результатов, исключение подмен и потерь.

Параллельно с внедрением электронных карт в 2009 г. появилось приложение «Электронная регистратура», в котором возможно с помощью портала государственных услуг и своего медицинского полиса записаться на прием к врачу, не выходя из дома. Все бо-

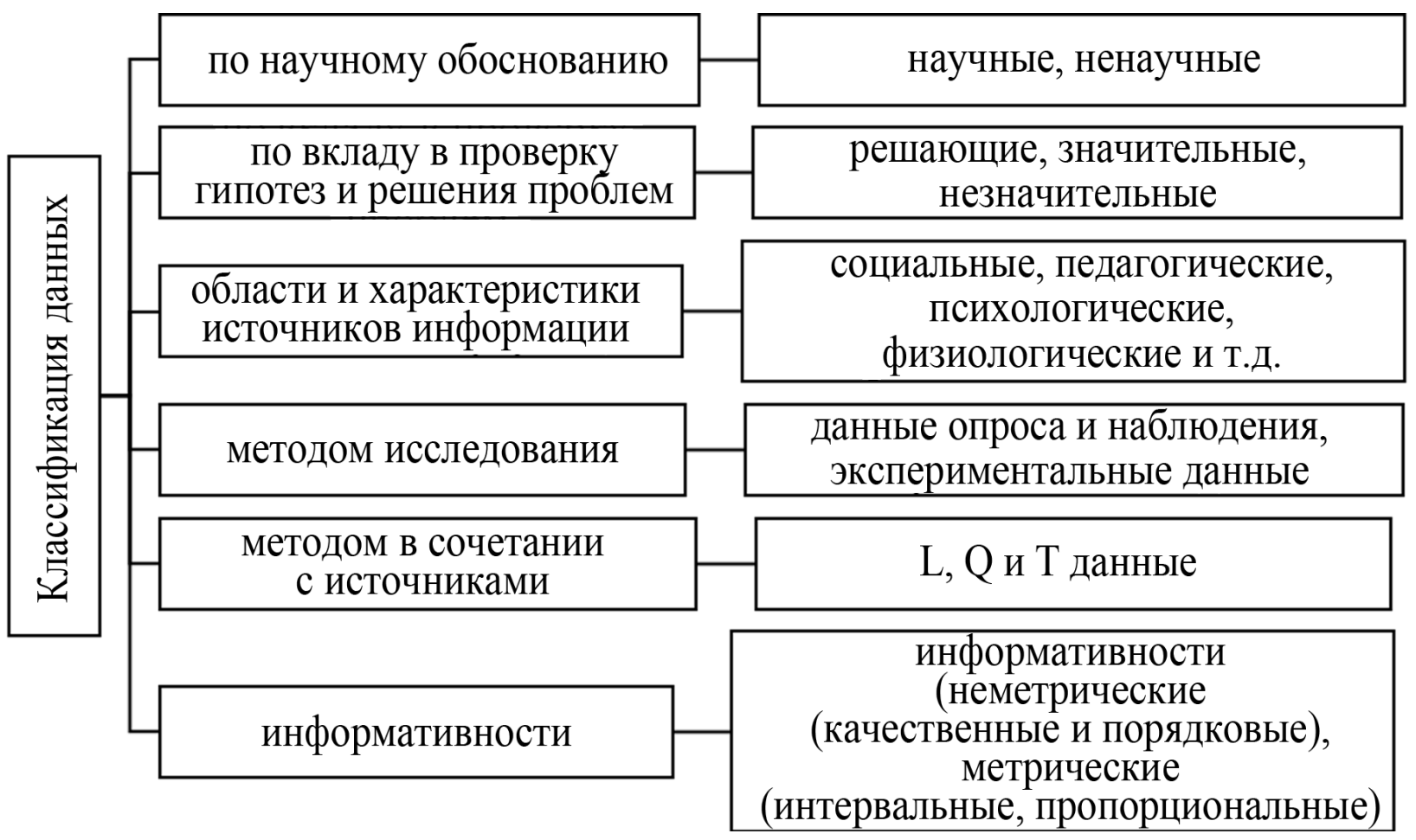

Рис. 1. Классификация данных [3] 
лее широкое распространение получают онлайн-консультации врачей по вопросам, которые не требуют посещения поликлиники [5].

Данные в сфере медицины являются конфиденциальной информацией и коммерческой тайной, что требует шифрования и кодирования. В настоящее время в сфере здравоохранения информация может быть зашифрована в четырех видах (рис. 2).

Обработка компьютерных данных представляет собой процесс изменения и корректировки содержания информации с помощью различных методов [1]. Технологии обработки компьютерной информации (данных) в медицинской сфере представлены на рис. 3 .

Рассмотрим централизованную обработку данных, которая в основном осуществляется в вычислительных центрах на высокопроизводительных и высокоточных компьютерах.
В данных центрах существуют специальные хранилища информации, которые защищены специальными кодами и оснащены средствами подготовки и выполнения документов. В большинстве случаев центры имеют в своем ведении медицинские учреждения определенного района, города, области, республики и подчинены определенным учреждениям управления здравоохранением. Персонал данного центра - медицинские работники, инженеры технических систем, дизайнеры, программисты, системные администраторы.

Децентрализованная обработка данных немного отличается от централизованной и получила свое развитие в период внедрения персональных компьютерных устройств, благодаря которым стало возможным вести карту пациента и просматривать все его назначения в условиях контрольных меропри-

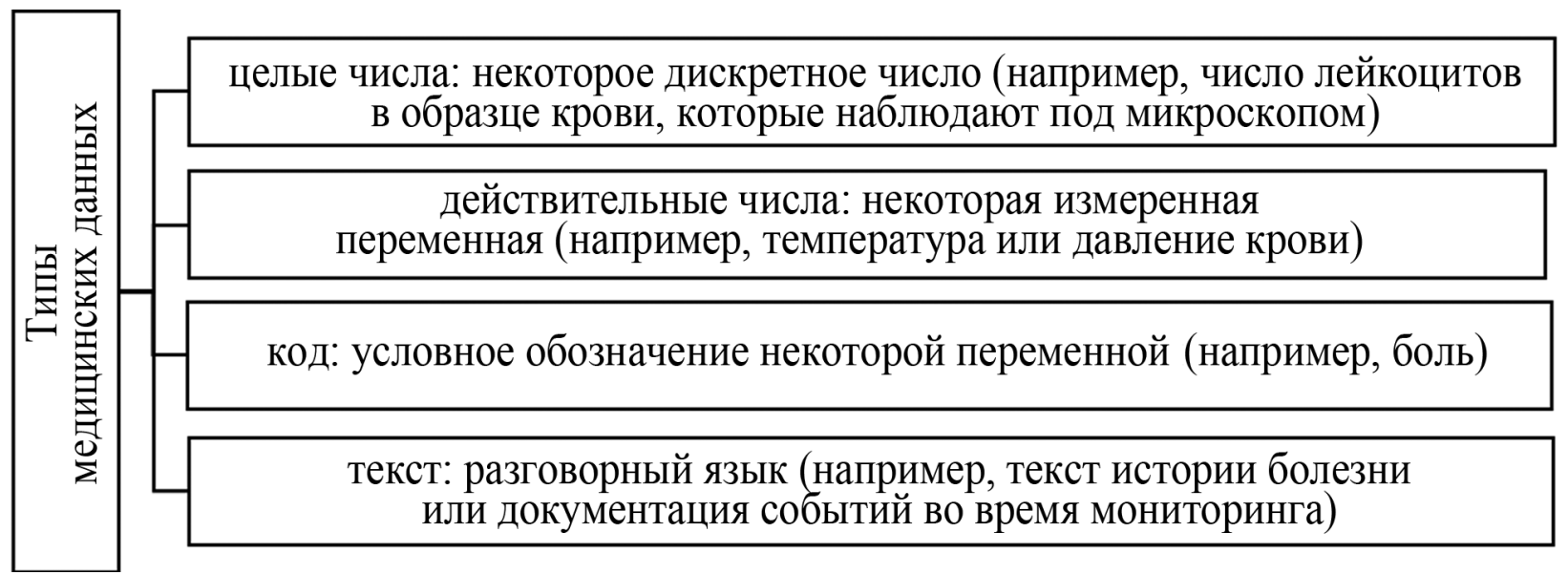

Рис. 2. Типы данных, которые используют

в документировании в системе здравоохранения

Технологии обработки информации в медицине

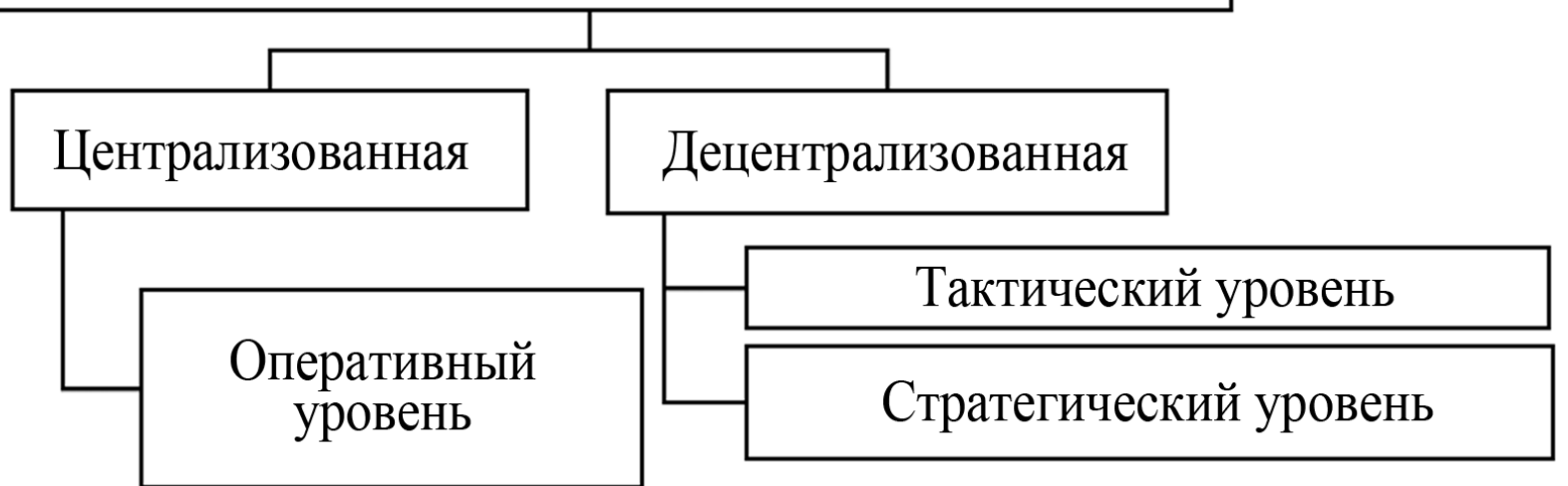

Рис. 3. Технологии обработки информации в сфере здравоохранения [7] 
ятий. Были созданы аппаратно-программные комплексы для графической работы и автоматизирования рабочего места (используются системы Медиолог, МедМес и другие) [5].

Обработка информации в сфере здравоохранения происходит в несколько уровней (этапов).

1. Оперативный (операционный) уровень. Основу деятельности и четко структурированные задачи на данном уровне выполняют работники медицинских учреждений и вспомогательные службы. Оперативный уровень является важным звеном во взаимодействии между пациентом и страховыми компаниями, аптеками и другими. Особенность данного уровня наличие одного из эффектов маркетинга.

2. Тактический уровень предназначен для обеспечения специалистов высшего и среднего звена, специалистов определенной отрасли и заведующих данным отделением. Основными задачами системы на данном уровне является возможность обеспечивать автономную работу (вести историю болезни, оформлять документы, иметь доступ к базам других учебных заведений, ведения отчетности).

3. Стратегический уровень используется только работниками высшего звена и связан с оптимальным управлением лечебным заведением на основе контроля и планирования. Наличие на данном уровне технологий, которые не были использованы ранее, — важная часть верного управленческого решения различных по сложности ситуаций, что показала на практике ситуация пандемического ограничения. Они базируются на региональных и государственных сетях и обеспечивают связь на разных уровнях.

Для исследования финансово-хозяйственной деятельности учреждения здравоохранения и выявления ошибок составления отчетности используют ревизию - метод финансового контроля. Для более детального рассмотрения понятия ревизии стоит обратить внимание на основные методы ее проведения, которые используются в данном виде проверки финансово-хозяйственной деятельности:

1) документальная ревизия;

2) фактическая ревизия;

3) методы экономического анализа аналитические процедуры;

4) организационные методы.

Ревизия в большинстве случае проводится поэтапно и состоит из пяти составляющих (рис. 4).

По причине того, что в медицинской сфере большая часть информации является конфиденциальной, проведение ревизии имеет свои определенные особенности. Оценка нарушений предполагает использование неконфиденциальной информации и отзывы самих пациентов системы здравоохранения.

Аналитическое исследование компьютерной обработки данных в сфере здравоохранения. При рассмотрении ревизии в медицинских учреждениях проводится рассмотрение финансов кассы и расчетных счетов, документов по финансово-хозяйственной деятельности, проверяется основная информация по расходам денежных средств, имуществу и качеству оказания услуг. В ревизии медицинских учреждений чаще всего используется метод встречных проверок: сличение документов бухгалтерии, рассмотрение услуг, по которым выданы счета.

Проверка в медицинских учреждениях происходит в несколько этапов:

- проверка правильности планирования расходов на содержание учреждений здравоохранения;

- проверка состояния бухгалтерского учета и достоверности отчетности.

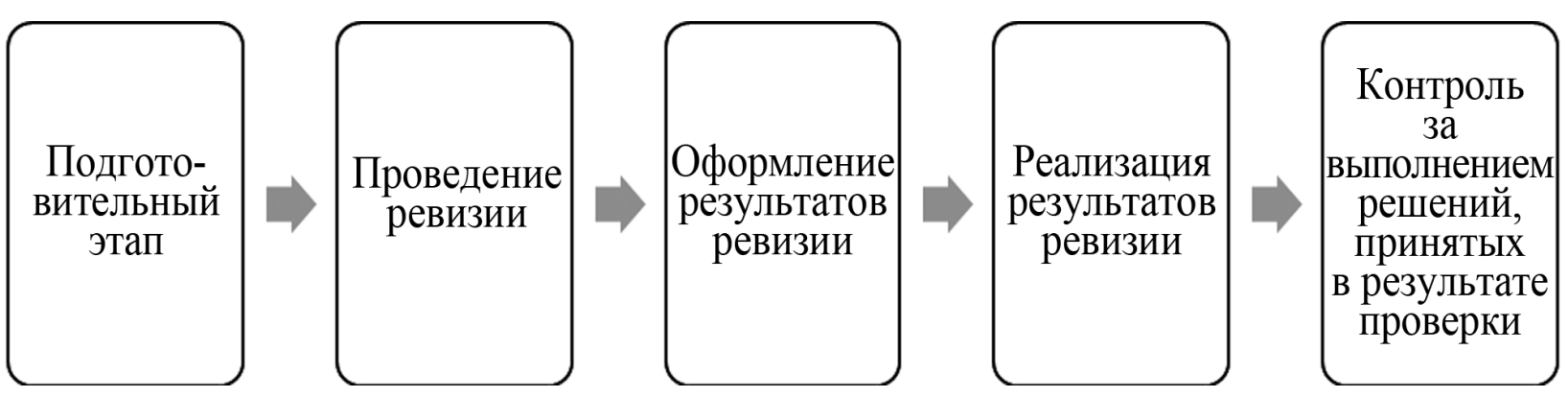

Рис. 4. Технологическая процедура проведения ревизии 
При анализе данных исследований, проводимых в системе здравоохранения, были выявлены определенные проблемы информатизации и цифровизации данной сферы. Рассмотрим основную классификацию проблем, которые присущи как частным, так и государственным учреждениям (рис. 5).

По результатам 8362 проверок в 3323 медицинских учреждениях было выявлено примерно $45 \%$ нарушений (рис. 6).
Как видно по представленным на рисунке 6 данным, большая часть нарушений именно прав пациента зависит от качества и доступности оказываемых услуг, меньше всего случаев составляет разглашение врачебной тайны и коммерческой информации. Согласно статистическим исследованиям данные нарушения в основном встречаются в отдаленных уголках России, например, в Регионах Сибири и Дальнего Востока [6].

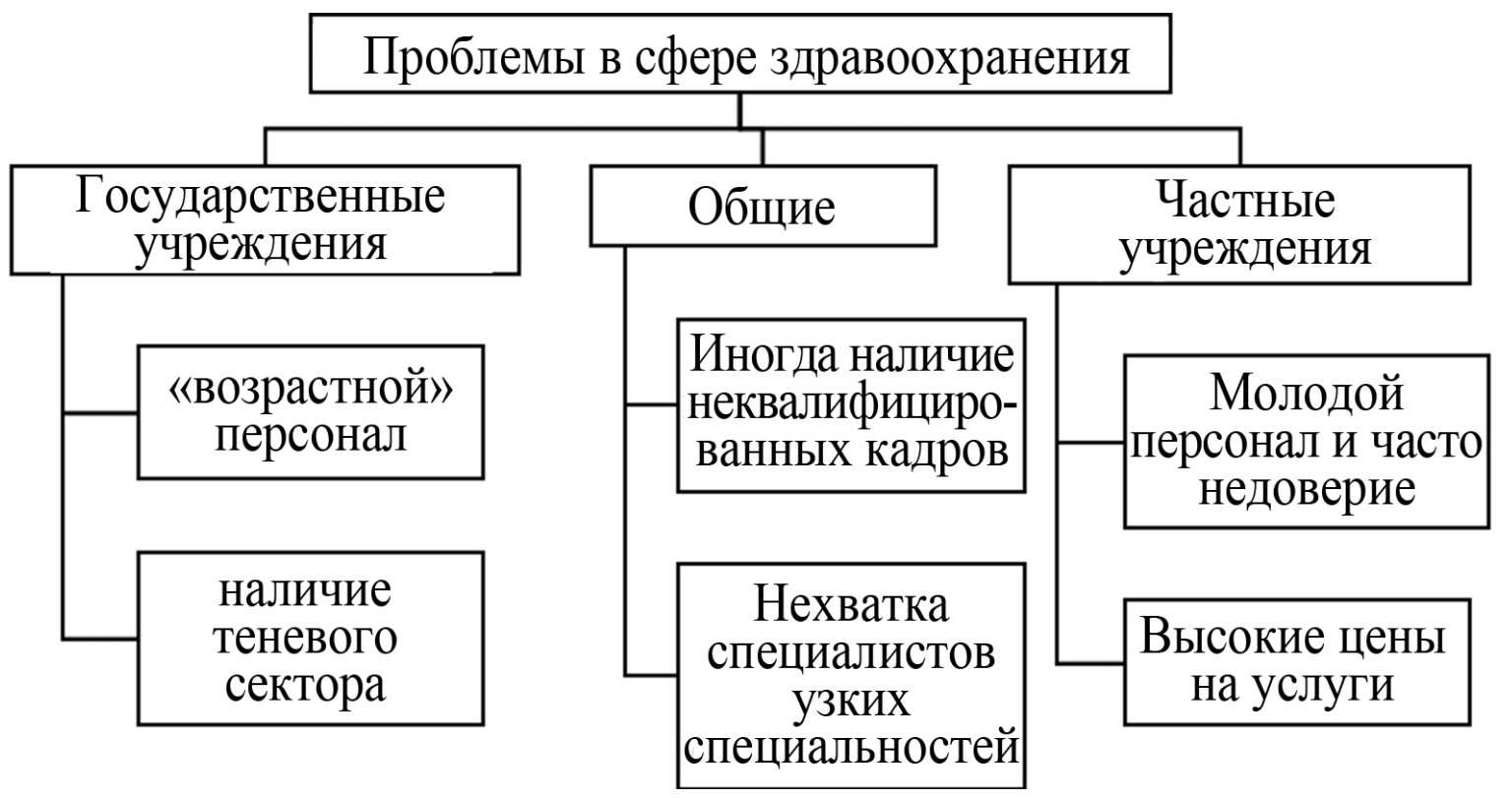

Рис. 5. Проблемы в сфере здравоохранения на 2019 г.

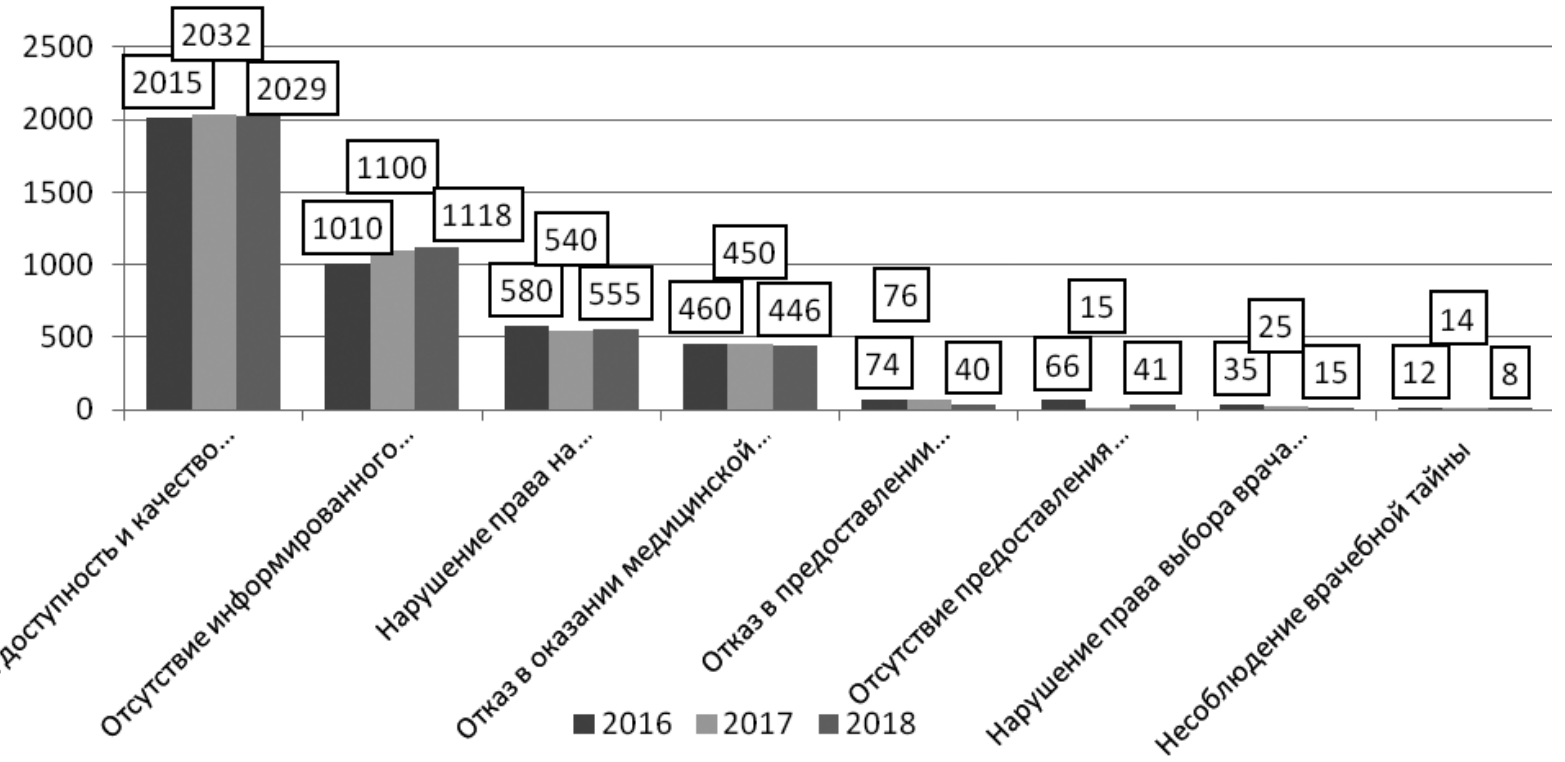

Рис. 6. Статистика нарушений прав граждан в сфере здравоохранения в Российской Федерации в 2016-2018 гг. 
В период распространения коронавирусной инфекции COVID-19 увеличилось число правонарушений, связанных с сокрытием информации о случаях выявления коронавирусных больных. В некоторых случаях тех, кто поступил с симптомами вируса, регистрируют как больных с пневмонией. Неверная информация поступает также и по смертности, так как число смертей в некоторые дни больше, чем указано в статистической информации, преподнесенной средствами массовой информации. При анализе статистических данных стоит отметить, что центров по борьбе с коронавирусной инфекцией было больше, чем требовалось, происходило увеличение цен на основные средства защиты, составляющих в некоторых случаях более 200 рублей за единицу. В практике существовали случаи, когда для снижения процента выявленных случаев COVID-19 людей регистрировали под иными фамилиями или же оставляли дома, но под строгим контролем врачей, что снижало процент официально зарегистрированных заболевших и использования препаратов клиниками и больницами, которые могли списываться не по назначению, а следовательно, это являлось нарушением. В практике оплаты были выявлены случаи, когда врачам, работавшим в «красной зоне», должны были выплатить начисленные и выделенные из бюджета средства, но в неко- торых регионах руководители медицинских учреждений отказались оказывать данную услугу по причине сокрытия информации и некорректного исполнения инструктивных документов системы здравоохранения, что увеличивало процент искажений отчетности о деятельности учреждений.

В настоящее время можно наблюдать следующие изменения ситуации в рамках нарушений (рис. 7).

Число некоторых правонарушений по сравнению с 2018 г. начало снижаться, иных, наоборот, увеличиваться, что может быть связано с политикой государства и возможностью корректировать данные посредством проникновения в конфиденциальную информацию.

Благодаря Федеральному закону «Об основах охраны здоровья граждан в Российской Федерации» от 21.11.2011 г. №323-Ф3 получилось снизить число нарушений в финансовой, экономической и технической сферах. В условиях компьютеризации при ревизии существуют как положительные, так и отрицательные факторы. При рассмотрении положительных факторов стоит отметить факт возможного проведения удаленной ревизии путем разрешения доступа к компьютеризированной информации, в противном случае применение информационных технологий в медицине усложняет рав боту самих врачей по контролю за данными, увеличивает число ошибок.

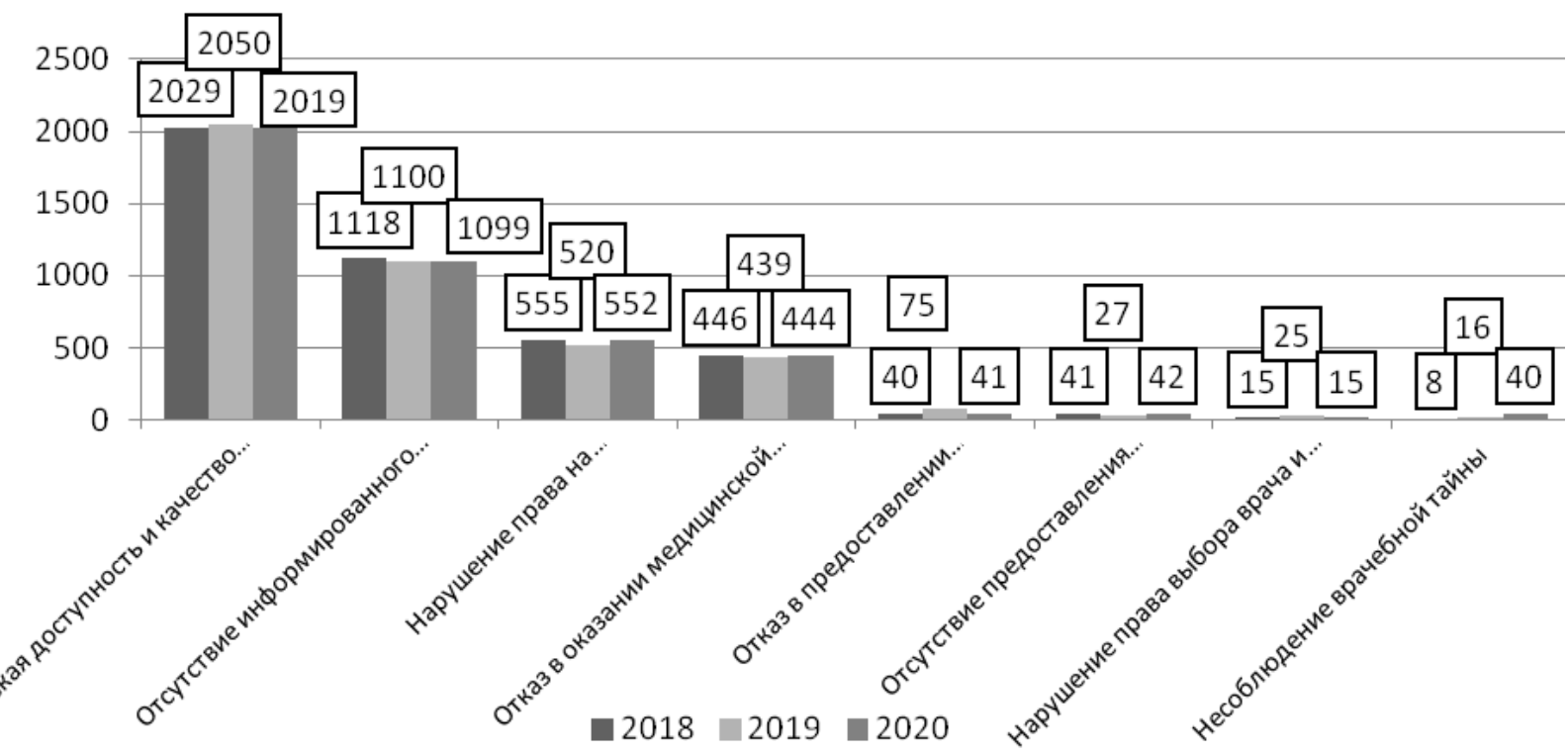

Рис. 7. Статистика нарушений прав граждан в сфере здравоохранения в Российской Федерации 2018-2020 гг. 
Заключение. При рассмотрении и анализе материалов ревизии в сфере здравоохранения стоит отметить, что многие государственные учреждения не используют электронное документирование информации по причине наличия пожилого персонала, который не всегда может справиться с технологиями в данной сфере. В свою очередь электронное документирование информации облегчает проверку и хранение важных результатов в сфере медицины и сохраняет их конфиденциальность. В период пандемии в 2020 г. большое влияние на доступность информации и ее отражение в информационных источниках оказывает государственная политика, которая, в свою очередь, имеет возможность искажать результаты для демонстрации результативности действий, тем самым в информационные средства вносятся не всегда корректные данные. Мы считаем, что требуется усилить контроль за данными системы здравоохранения и таким образом снизить вероятность подмены информации и неверного толкования данных. В перспективе для доступа пациента к своей карте и использования материалов для консультации с большим числом врачей будут введены специальные коды.

\section{Литература}

1. Воронина Н.В., Зубарева Е.В. Цели и задачи проведения ревизии, порядок планирования и проведения ревизии // Бухгалтерский учет: достижения и научные перспективы 21 века. - 2017. - С. 60-64.

2. Лисиџын Ю.П., Калмыков А.А., Сенченко А. Ю. Концепция стабилизации и развития - стратегия развития учреждений здравоохранения // Экономика здравоохранения. - 2005. - С. 20-24.

3. Соболева Е.А. Эволюция модели финансирования здравоохранения РФ // Экономика и бизнес: теория и практика. - 2019. C. 67-75.

4. Информационные технологии в сфере здравоохранения [Электронный ресурс]. Режим доступа: http://mirror-info.ucoz.com/ medicine/InfoTecMed.pdf (Дата обращения: 02.09.2020).

5. ИТ в медицине 2020 [Электронный pecypc]. - Режим доступа: https://ict2go.ru/ events/17810/ (Дата обращения: 16.09.2020).
6. Какие ошибки и нарушения допустили в медицинской сфере: доклад Росздравнадзора [Электронный ресурс]. - Режим доступа: https://www.snta.ru/press-center/kakie-oshibkii-narusheniya-dopustili-v-meditsinskoy-sferedoklad-roszdravnadzora/ (Дата обращения: 29.09.2020).

7. Ревизия в условиях применения компьютерных технологий [Электронный ресурс]. - Режим доступа: https://ekonom-buh. ru/referaty-po-bukhuchetu/349-reviziya-vusloviyakh-primeneniya-kompyuternykhtekhnologij.htm (Дата обращения: 14.09.2020).

8. Coronavirus (Covid-19) [Электронный pecypc]. - Режим доступа: https://coronavirusmonitor.ru/ (Дата обращения: 19.09.2020).

\section{Referenses}

1. Voronina N.V., Zubareva E. V. Celi i zadachi provedenija revizii, porjadok planirovanija i provedenija revizii [Goals and objectives of the audit, the order of planning and conducting the audit] // Buhgalterskij uchet: dostizhenija i nauchnye perspektivy 21 veka [Accounting: achievements and scientific prospects of the $21 \mathrm{st}$ century]. — 2017. - Pp. 60-64.

2. Lisicyn Ju. P., Kalmykov A.A., Senchenko A. Ju. Koncepcija stabilizacii i razvitija strategija razvitija uchrezhdenij zdravoohranenija [Concept of stabilization and developmentstrategy for the development of health care institutions] // Jekonomika zdravoohranenija [Health economics]. - 2005. - Pp. 20-24.

3. Soboleva E.A. Jevoljucija modeli finansirovanija zdravoohranenija RF [Evolution of the model of healthcare financing in the Russian Federation] // Jekonomika i biznes: teorija i praktika [Economics and business: theory and practice]. - 2019. - Pp. 67-75.

4. Informacionnye tehnologii $\mathrm{v}$ sfere zdravoohranenija [Information technologies in the field of healthcare] [Jelektronnyj resurs]. URL: http://mirror-info.ucoz.com/medicine/InfoTecMed.pdf (Date accessed: 02.09.2020).

5. IT v medicine 2020 [IT in medicine 2020] [Jelektronnyj resurs]. — URL: https://ict2go.ru/ events/17810/ (Date accessed: 16.09.2020).

6. Kakie oshibki i narushenija dopustili v medicinskoj sfere: doklad Roszdravnadzora [What mistakes and violations were made in the medical sphere: report of Roszdravnadzor] 
[Jelektronnyj resurs]. — URL: https://www. snta.ru/press-center/kakie-oshibki-i-narusheniya-dopustili-v-meditsinskoy-sfere-dokladroszdravnadzora/ (Date accessed: 29.09.2020).

7. Revizija $\mathrm{v}$ uslovijah primenenija komp'juternyh tehnologij [Revision in the conditions of application of computer technologies]
[Jelektronnyj resurs]. — URL: https://ekonombuh.ru/referaty-po-bukhuchetu/349-reviziyav-usloviyakh-primeneniya-kompyuternykhtekhnologij.htm (Date accessed: 14.09.2020).

8. Coronavirus (Covid-19) [Jelektronnyj resurs]. - URL: https://coronavirus-monitor.ru/ (Date accessed: 19.09.2020).

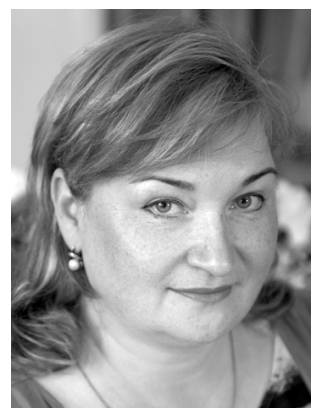

Голощапова Людмила Вячеславовна - кандидат экономических наук, доцент базовой кафедры финансового контроля, анализа и аудита Главного контрольного управления города Москвы Российского экономического университета имени Г.В. Плеханова.

Goloshchapova Liudmila Vyacheslavovna - Candidate of Economic Sciences, Associate Professor of the Basic Department of Financial control, Analysis and Audit of the Main Control Department of Moscow, Plekhanov Russian University of Economics.

117997, г. Москва, Стремянный пер., 36

36 Stremyanny ln., 117997, Moscow, Russia

E-mail: cool.lvg2012@yandex.ru

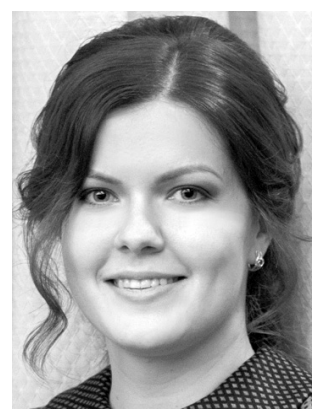

Савина Наталья Павловна - кандидат экономических наук, доцент кафедры мировой экономики Российского экономического университета имени Г. В. Плеханова.

Savina Natalia Pavlovna - Candidate of Economic Sciences, Associate professor of World Economy Department, Plekhanov Russian University of Economics.

117997, г. Москва, Стремянный пер., 36

36 Stremyanny ln., 117997, Moscow, Russia E-mail: Savina.NP@rea.ru 


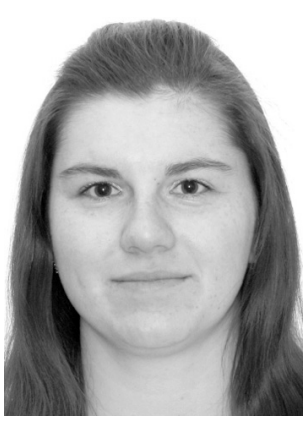

Винидиктова Ксения Александровна - специалист 4 курса, направление подготовки «Экономическая безопасность» Российского экономического университета имени Г.В. Плеханова.

Vinidiktova Ksenia Alexandrovna - 4th-year specialist, Department of Economic Security, Plekhanov Russian University of Economics.

117997, г. Москва, Стремянный пер., 36

36 Stremyanny ln., 117997, Moscow, Russia

E-mail: ksenia.vinidiktova@yandex.ru 